\title{
On the Current Situation and Countermeasures of Tourism Culture Communication_-Taking Chongqing as an Example
}

\author{
Long Zhang \\ School of Management, Chongqing College of electronic engineering, Chongqing 401331, China.
}

Keywords: tourism culture communication, communication subject, media, Chongqing.

\begin{abstract}
The spread of tourism culture will help to enhance the competitiveness of cities and attract more tourists. This paper takes Chongqing as an example to analyze the current situation of tourism culture, and points out that there are many problems such as the over unitary of communication subject, the lack of cultural connotation and the shortage of media integration in Chongqing. Therefore, Chongqing should optimize the main structure of communication, dig deep local context, multi-media integration and dissemination, to attract more tourists, promote the sustainable development of Chongqing tourism.
\end{abstract}

\section{Current Situation}

Tourism as one of the world's three pillar industries, occupies an important position in the national economy and enjoy the reputation of "smoke-free industry" and "forever sunrise industry". With the rapid development of tourism, how can one of the tourist destinations come to the forefront to attract tourists is the key issue of regional tourism. Research shows that good tourism and cultural communication will greatly affect people's tourism decision-making, and is one of the key factors to attract tourists. At the same time, it can make the tourist destination accept better reputation and popularity, so as to get a good society efficiency, economic benefits and ecological effect, and make further efforts to obtain a higher status in the tourism market. Therefore, the study of tourism culture communication is feasible and necessary.

Chongqing is located in the southwest of China, the upper reaches of the Yangtze River area. It has 38 districts and counties which accommodate population of 30.72 million people. What's more, it is China's fourth central municipality and national central city. Chongqing as a metropolis is rich in its tourism resources, which include mountain, river and historical culture. It is also a famous tourist attraction in China, which was titled "China Excellent Tourism City" in 2000. Represented by gorge scenery, Chongqing tourism resources set mountains, water, forest, spring, waterfall, gorge, hole as a whole, integrat Bayu culture, national culture, the Three Gorges culture, accompany the Peidu culture, food culture in a unity. During 18 years, especially when the Chongqing municipal government in September 14, 2013 laid out the "five major functional areas of Chongqing" strategy, the tourism industry has been leap-forward development. According to the latest statistics, 2014 received a total of 349 million tourists at home and abroad, which increased $13.2 \%$ over the previous year; and total tourism income of 2003.37 billion yuan, an increase of 13.1\%. On the list Forbes released about 2014 China's most developed tourism tourism city, Chongqing ranked third in the country ${ }^{[1]}$. However, compared with other provinces and cities in the country, Chongqing, the tourism industry still have many problems which hindered the rapid development of tourism in Chongqing. This paper will discuss the current situation and countermeasures of tourism culture communication in Chongqing from the perspective of Communication studies, aiming to promote the sustainable development of tourism in Chongqing, and provide some reference ideas and suggestions for the development of other regional tourism. 


\section{Problems Exist on Communication}

\section{1) The Singularity of Communication Subject}

The subject of tourism culture comnunication includs government departments, tourism agencies, the public as well as tourists. They are not only the subject of communication activities, but also the initiator, the organization and individual by initiatively introduce information to the audience. The communicator is responsible for those informative job, like collection, collation, selection, processing, etc, and then spread, in this way, they are the gatekeeper of communication activities ${ }^{[2]}$. The government departments that is responsible for tourism and cultural communication of Chongqing are Chongqing radio and television stations, Chongqing Tourism Bureau and other communications sector. Communication departments through the guidance and coordination of television, radio, newspapers, Internet and other media forms, transmit the Chongqing tourism information externally. Since 2011, they mainly operated a project called "Chongqing, simply must go", around the theme they launched activities like invited cultural celebrities to promote Chongqing, advertised on CCTV and other well-known media, hold international tourism and cultural events and other activities, and all of them received good results in the community. However, in addition to the government, the rest majority of tourism and cultural communicators are lack of subject consciousness, awareness and sense of service, and they failed to join the spread of them. According to the survey and analysis, there are only 26 people who know the slogan of tourism image in Chongqing, accounting for only $9.6 \%$ of the survey. And only five of the tourists know Chongqing tourism image, only $2 \%$ of the surveyed number. There are few tourism enterprises in Chongqing propagate tourism image, few companies use the image of Chongqing slogan and logo, all business propaganda is around their own products, and they did not form a whole image of Chongqing tourism. On the spreading of image propagation, they took a free ride of the government, thought that this is the government's obligation to propaganda in the image, and do not want to pay for the effort and money ${ }^{[3]}$.

2) The Lack of Communication Media Combination

Ma Bo pointed out in the Modern Tourism Culture: "cultural factors penetrate in all aspects of modern tourism activities, culture is the starting point and the return point of tourists, is the attractive edge of tourist landscape, is the soul of tourism" ${ }^{[4]}$. Chongqing is a city with history of three thousand years. The regional culture occupies a pivotal position in the culture of our country, however, in the urban tourism culture, Chongqing's regional culture is not enough to be highlighted. According to data analysis, seeing from the city promotion slogans, Chongqing has always set the slogan, such as "high gorge Pinghu", "the world's Chongqing, the eternal Three Gorges", "the city of landscape, the beautiful capital" and so on, which made Chongqing's natural scenery as the starting point, and "passion Chongqing" and "Chongqing, simply must go" also failed to reflect the cultural characteristics. From the film and television works, although the "Chongqing, simply must go" promotional film was put on the CCTV, and there are 15 seconds to show the Yangtze River Three Gorges, the Heavenly Pit and Earthly Ravine, Dazu Rock Carvings, Three Natrual Bridges, White Crane Ridge and Dioyu cheng five typical tourist attractions, and the picture is exquisite. However it still can not clearly express the venerable Bayu culture. Therefore, the tourists' cultural impression of Chongqing still remain in the "hot pot", "beauty", "beautiful landscape" and other superficial level, cultural resources can not be counted to them.

\section{3) The Superficial Media Integration}

Media integration refers to breaking the boundaries of traditional media and new media, not confined to one medium in the dissemination, but the comprehensive use of various media forms, such as pictures, text, video, audio, etc., to display a subject in wide range and Three-dimensional way. Different from the traditional media single-point, single-platform communicative method, media integration can achieve multi-platform, multi-channel, personalized, interactive communication ${ }^{[5]}$. Chongqing in the aspect of tourism and cultural communication did not grasp the integration of media in-depth, more media was fixed in the traditional medium. Although it also began to use microblog, 
WeChat and other new media technology, the level of application for new media is still low, and it did not firmly grasp the development trend of network media. Specifically, in the choice of traditional media, take television advertising as an example, the frequency and scope of the the Chongqing tourism propagation advertising is lower than Shandong, Shaanxi and other developed tourism provinces, while the media level standards did not reach the highest, the application of international, national media is less. By the Chongqing tourism government departments report, Chongqing, the budget for the tourism image publicity and management each year is over 30 million yuan, and the cost for Shanghai annual image marketing is about 60 million yuan, 55 million yuan in Zhejiang Province, about 50 million in Jiangsu Province ${ }^{[6]}$. About the choice of new media, take microblog as an exmple, in terms of Sina microblogging February 2014 government tourism bureau influence rankings, the Chongqing Municipal Tourism Bureau official microblog ranked $15^{\text {th }}$. Champion on the list is Qingdao Tourism Bureau official microblog which released 2,000 more microblog than Chongqing's, and the number of Chongqing's fans is only a fraction of it, from this aspect, we can see the impact of Chongqing Tourism Bureau is expected to be improved.

\section{Measures to Communication Problem}

1) Optimizing the Subject of Communication

Advanced tourism cultural communication should optimize the communicator structure, pay attention to the interpersonal communication effect of the communicator, and form a complex communication system of " guidance of government, active participation of the masses and propagation of tourists". At present, the main subject of tourism culture communication in Chongqing is the government, led by government propaganda department and tourism department. Therefore, the government and tourism department as a guide should carry out the main propaganda strategy, and construct high-quality communication team. First of all, they should pay attention to the cultivation and introduction of talents. They should actively absorb and train marketing talents, tourism professionals and news media talents, to form a good communication team, and employ well-known experts and scholars at home and abroad to seek advice of Chongqing tourism image communication activities, to invite certain social celeberty as the image ambassador to enhance the visibility of Chongqing. Second, to enhance the local public pride and sense of communication, making people consciously joined the ranks of tourism and cultural communication. Chongqing municipal government departments should hold attractions activities like local residents free tour regularly, so that residents can participate in tourism activities. in the tourism process, they can feel the government departments' expectations to the city's tourism image. Accroding to this, their passion that speading their city's travel image and being a part of Image will be stimulated, so that ordinary people will consciously join the spread of Chongqing tourism image. The final step is to mobilize the tourists to actively spread, and form word-of-mouth effect. Chongqing municipal government departments should regularly organize activities to appeal visitors to spread Chongqing tourism culture in their own interpersonal circle, such as tourism photography contest, which convey the beauty of tourism by image ; and sweepstakes, also visitors can share their own feeling during travel with words and photos in the social media, through each visitor's interpersonal circle to expand the interpersonal communication effect, to form word-of-mouth effect, so as to stimulate the potential tourists travel requirement.

\section{2) Digging Local Culture Deeply}

Cultural is the root of tourism, tourism inherit culture, culture is the soul of tourism. Tourism culture communication should be based on the local tourism resources and tourism characteristics, highlighting the localization characteristics. Chongqing regional culture is long standing and well established, and was formed a unique folk culture, being an important city label. However, the current development of regional culture in Chongqing is not enough, and is lack of tourism image connotation. Therefore, Chongqing should collect all kinds of tourism resources to the regional 
framework of Chongqing culture, highlighting the cultural characteristics of Chongqing. At the same time, fusing the cultural connotation of Chongqing into the whole communication and promotion work, since it is conducive to enhance the continuity of Chongqing tourism image communication, promote the development of urban tourism industry. For example, during World War II, Chongqing was the international famous city, same as Washington, London, Moscow, and was the country's political, military, economic, cultural and diplomatic center. Peidu culture has become the unique cultural type of Chongqing, the relevant departments should base on the protection of these cultural relics, advance with the times, combine the city image of red culture, modern Chongqing tenacity and fearless of difficult, dig spiritual wealth deeply, create distinctive cultural brand.

\section{3) Integrating Multimedia}

With the advent of the information age and the popularity of the Internet application, the diversity of the media is more prominent, if blindly choose the traditional media, then the effectiveness of communication will be reduced very likely and can't gain ideal income on the basis of the high input. So the only method we can adopt to disseminate tourism image is to utilize the characteristics of credibility and the depth of the content of the traditional media, and the efficiency of information spreading and grassroots advantages of new media, to take advantage from a variety of media, combine a variety of media. A variety of media being integrated shall meet the needs of tourism image spreading. Chongqing should continue to adhere to the traditional media dissemination of Chongqing tourism, give full play to the traditional media's characteristics of credibility and authority of newspapers, television and other, emphesize the in-depth advantage of reports, releasing authoritative voice, focusing on the dissemination of Chongqing cultural connotation. With the superiority of traditional media in-depth coverage, launched a series of Chongqing tourism introduction in the newspaper, television and other traditional media, spreading the image of tourism from multiple angles. About the new media, Chongqing should use the characteristic of quick information release and grassroots advantages, improve the portal site construction, detaile the introduction of Chongqing tourism image. At the same time, official released microblog content is to be optimized, to highlight the role of image communication. To adhere to the development of WeChat platform, while refineing of the contents, WeChat advisory services should be developed, so that visitors can access the practical information on the WeChat directly

\section{Conclusion}

In short, tourism culture communication research is a very complex and systematic engineering research, covering a wide range of knowledge, involving economic, social, cultural, political and other aspects. In addition to the theoretical and data analysis, but also the need for specific methods discussion, such as how to use a variety of media to carry out the dissemination and the market analysis of the audience need to be further explored and research. The subject of tourism culture communication in Chongqing is a government-led communication activity, which is spread through tourism slogans, promo films and festival activities. Traditional media communication plays a major role in the carrier of communication. Therefore, Chongqing tourism culture not only need to deepen the local cultural characteristics, shaping the cultural brand, innovatiog while inheriting, but also operate with the government departments and other management, keep the systmatic maintenance work of image dissemination. Only in this way can we attract more tourists, more importantly, can promote the sustainable development of urban economy, so that the tourism culture in Chongqing can get good effect. 


\section{References}

[1] 2014 Chongqing Tourism Statistics Bulletin, Chongqing Tourism Bureau, January 15, 2015 Http://www.cqta.gov.cn/cquinfo/View.aspx?id=8718/

[2] Shi Peiji, Li Xianfeng. Tourism Image Communication Research [J]. Journal of Southwest University for Nationalities (Humanities and Social Sciences). 2006 (8).

[3] Liang Tao. Chongqing Tourism Image Marketing Strategy Research [D]. Southwest University. 2009.

[4] Ma Bo. Modern Tourism Culture [M]. Qingdao: Qingdao Press, 2012.12.

[5] Zhang Guoping. Information Dissemination in the Process of Information Asymmetry [J]. News Lovers .2010 (4)

[6] Wu Bihu. Regional Tourism Planning Principles [M]. Beijing: China Tourism Press, 2001.210. 